\title{
Top Priorities For Health Service Improvements among Australian Oncology Patients
}

\author{
Dr Jamie Bryant* \\ University of Newcastle, School of Medicine and Public Health, Australia
}

\begin{abstract}
Objective: To determine among a sample of Australian cancer patients receiving outpatient oncology care: (1) The most frequently endorsed general health service improvements selected by patients; (2) For the three most endorsed general health service improvements, the proportion of participants endorsing specific health service changes; and (3) sociodemographic, disease and treatment characteristics associated with the most frequently endorsed general health service improvements.
\end{abstract}

Methods: A cross-sectional survey was conducted across six outpatient oncology treatment units located in New South Wales, Australia. Patients receiving chemotherapy for any cancer diagnosis at any of six oncology services were recruited. Participants completed an online survey which included the Consumer Preferences Survey. Logistic regression analyses were conducted to identify sociodemographic, disease and treatment characteristics associated with frequently endorsed health service improvements.

Results: A total of 879 eligible patients initiated the survey (72\% consent rate). Participants selected a median of two health service improvements. The three most wanted improvements were car parking (56\%), up-to-date information about treatment or condition progress (19\%), and hospital catering (17\%). Age was the only characteristic significantly associated with identifying car parking as a needed improvement.

Conclusion: Achieving high quality cancer care requires understanding of the views and experiences of patients about the quality of care they receive. Car parking and access to information were the two most frequently endorsed general health service changes desired by this sample of participants

Practice implication: Future studies could examine whether enacting changes as per patient feedback improves patient perceptions of quality of care, and health outcomes.

Keywords: Patient-Cantered Care; Cancer; Quality of Healthcare; Patient identified change

\section{BACKGROUND}

\section{Patient-centred cancer care is considered optimal health care}

Patient-centred care is defined by the Institute of Medicine as care that is respectful of, and responsive to, individual patient preferences, needs and values [1]. Patient-centred care is considered one of six key elements of high-quality care[1]. In the field of cancer care, provision of patient-centred care has been associated with improved psychological outcomes [2], increased medication adherence [3] and increased patient satisfaction [4, 5]. In order to achieve high-quality patient-centred care, it is imperative that we understand the views and experiences of patients about the quality of care they receive, and use these perspectives to inform quality improvements to the healthcare system [6].

\section{Accurate, efficient and clinically useful methods are needed to capture patient's perspectives}

A commonly used method of examining and understanding patient perceptions of the quality of care received is via patient satisfaction surveys or surveys of unmet needs. Such surveys ask patients to either reflect on the care they have received, or report any needs that could be addressed by healthcare providers and/ or the healthcare system. These approaches, however, have many well-documented limitations [7-9]. Firstly, most surveys only assess patient's perceptions on the broad aspects of care, rather than

*Correspondence to: Dr. Jamie Bryant, University of Newcastle, School of Medicine and Public Health, Australia, Tel: 0240420709, Email: uonsenquiry@ newcastle.edu.au; Jamie.Bryant@newcastle.edu.au

Received: May 05, 2021; Accepted: May 11, 2021; Published: May 18, 2021

Citation: Bryant J (2021) Impact of Aneurysm Care Oriented Program on Knowledge Regarding Post-Operative Care of Cerebral Aneurysm Patients Among Nurses in a Tertiary Care Hospital of North India for Consideration for Publication. J Pat Care 7:159.

Copyright: (C) 2021 Bryant J. This is an open-access article distributed under the terms of the Creative Commons Attribution License, which permits unrestricted use, distribution, and reproduction in any medium, provided the original author and source are credited. 
exploring the specific improvements they would like made [7, 10]. Obtaining more detailed information from patients about specific strategies that they perceive would improve their care, would reduce ambiguity as to what changes are seen by patients as most necessary, thus providing more concrete information that may help to better guide changes initiated by the healthcare system [9]. Secondly, inadequacies in psychometric rigor and difficulties in scoring many of the frequently used patient satisfaction and unmet needs surveys have been identified [11].

In response to these shortcomings, a new tool titled 'The Consumer Preferences Survey' (CPS) was developed to allow collection of detailed data about patient desired health service improvements [10]. The CPS is computer administered and uses dynamic branching software to allow users to endorse both general and specific actionable changes that would help improve their care and experiences. The CPS was developed using a systematic process that included a literature review, advice and feedback from an expert advisory group, and pilot testing [12]. The measure has good acceptability, face validity and adequate test-retest and internal reliability for most items [13]. Unlike previous surveys, the CPS provides a list of concrete and specific changes that patients perceive could be improved [13] (Tables 1-3).

\section{Consumer Preferences Survey data from large heterogeneous samples of cancer patients will help to inform health care improvements}

To date, only two studies have used the CPS to explore cancer

Table 1: Sample characteristics $\left(\mathrm{N}=879^{*}\right)$.

Column totals may not add to total sample size due to missing values. Percentages may not add to 100 due to missing values.

\begin{tabular}{|c|c|c|c|}
\hline & & $\mathrm{N}$ & $\%$ \\
\hline \multirow[t]{3}{*}{ Age } & $18-49$ & 157 & 17.9 \\
\hline & $50-69$ & 449 & 51.1 \\
\hline & $70+$ & 269 & 30.6 \\
\hline \multirow[t]{2}{*}{ Gender } & Male & 392 & 44.6 \\
\hline & Female & 487 & 55.4 \\
\hline \multirow{3}{*}{$\begin{array}{l}\text { Highest level of } \\
\text { education }\end{array}$} & High school or lower & 581 & 66.1 \\
\hline & Diploma or Trade Certificate & 177 & 20.1 \\
\hline & Bachelor or Post-grad degree & 113 & 12.9 \\
\hline \multirow[t]{2}{*}{ Marital status } & Married or living with partner & 574 & 65.3 \\
\hline & $\begin{array}{l}\text { Single (never married, divorced, } \\
\text { widowed) }\end{array}$ & 294 & 33.4 \\
\hline \multirow{2}{*}{$\begin{array}{l}\text { Aboriginal or } \\
\text { Torres Strait } \\
\text { Islander }\end{array}$} & Yes & 32 & 3.6 \\
\hline & No & 838 & 95.3 \\
\hline \multirow{2}{*}{$\begin{array}{l}\text { Concession } \\
\text { card }\end{array}$} & Yes & 579 & 65.9 \\
\hline & No & 291 & 33.1 \\
\hline \multirow{2}{*}{$\begin{array}{l}\text { Private health } \\
\text { insurance } \\
\text { status }\end{array}$} & Yes & 335 & 38.1 \\
\hline & No & 535 & 60.9 \\
\hline \multirow{6}{*}{$\begin{array}{l}\text { Weekly Family } \\
\text { income }\end{array}$} & $<\$ 300$ per week & 82 & 9.3 \\
\hline & $\$ 300-\$ 499$ per week & 264 & 30.0 \\
\hline & $\$ 500-\$ 799$ per week & 153 & 17.4 \\
\hline & $\$ 800-\$ 1000$ per week & 87 & 9.9 \\
\hline & $>\$ 1000$ per week & 115 & 13.1 \\
\hline & Prefer not to answer & 170 & 19.3 \\
\hline
\end{tabular}

Table 2: Disease and treatment characteristics $\left(\mathrm{N}=879^{*}\right)$.

\begin{tabular}{|c|c|c|c|}
\hline & & $\mathrm{N}$ & $\%$ \\
\hline \multirow{11}{*}{$\begin{array}{l}\text { Site of primary } \\
\text { cancer }\end{array}$} & Blood & 211 & 24.0 \\
\hline & Breast & 193 & 22.0 \\
\hline & Bowel & 165 & 18.8 \\
\hline & Lung & 74 & 8.4 \\
\hline & Other & 64 & 7.3 \\
\hline & $\begin{array}{l}\text { Gynaecological, including } \\
\text { ovarian }\end{array}$ & 42 & 4.8 \\
\hline & Prostate & 31 & 3.5 \\
\hline & Pancreatic (stomach) & 31 & 3.5 \\
\hline & Head and Neck & 25 & 2.8 \\
\hline & Liver & 16 & 1.8 \\
\hline & Melanoma & 11 & 1.2 \\
\hline \multirow{3}{*}{$\begin{array}{l}\text { Purpose of } \\
\text { treatment }\end{array}$} & Curative & 413 & 47.0 \\
\hline & $\begin{array}{l}\text { Slow growth or reduce } \\
\text { symptoms }\end{array}$ & 418 & 47.6 \\
\hline & Unsure & 35 & 4.0 \\
\hline \multirow[t]{8}{*}{$\begin{array}{l}\text { Type of treatments } \\
\text { received }\end{array}$} & $\begin{array}{l}\text { Radiation therapy } \\
\text { Yes } \\
\text { No }\end{array}$ & $\begin{array}{l}217 \\
646\end{array}$ & $\begin{array}{l}73.5 \\
24.7\end{array}$ \\
\hline & $\begin{array}{l}\text { Chemotherapy } \\
\text { Yes } \\
\text { No }\end{array}$ & $\begin{array}{c}824 \\
39\end{array}$ & $\begin{array}{c}93.7 \\
4.4\end{array}$ \\
\hline & $\begin{array}{l}\text { Hormone therapy } \\
\text { Yes } \\
\text { No }\end{array}$ & $\begin{array}{c}59 \\
804\end{array}$ & $\begin{array}{r}6.7 \\
91.5\end{array}$ \\
\hline & $\begin{array}{l}\text { Biological therapy } \\
\text { Yes } \\
\text { No }\end{array}$ & $\begin{array}{c}19 \\
844\end{array}$ & $\begin{array}{l}2.2 \\
96\end{array}$ \\
\hline & $\begin{array}{l}\text { Bone marrow transplant } \\
\text { Yes } \\
\text { No }\end{array}$ & $\begin{array}{c}11 \\
852\end{array}$ & $\begin{array}{c}1.3 \\
96.9\end{array}$ \\
\hline & $\begin{array}{l}\text { Stem cell transplant } \\
\text { Yes } \\
\text { No }\end{array}$ & $\begin{array}{c}25 \\
838\end{array}$ & $\begin{array}{c}2.8 \\
95.3\end{array}$ \\
\hline & $\begin{array}{l}\text { Surgery } \\
\text { Yes } \\
\text { No }\end{array}$ & $\begin{array}{l}341 \\
522\end{array}$ & $\begin{array}{l}38.8 \\
59.4\end{array}$ \\
\hline & $\begin{array}{l}\text { None of these } \\
\text { Yes } \\
\text { No }\end{array}$ & \multicolumn{2}{|c|}{$\begin{array}{c}16 \\
847\end{array}$} \\
\hline \multirow{4}{*}{$\begin{array}{l}\text { Number of visits } \\
\text { to the out-patient } \\
\text { clinic in the } \\
\text { previous } 3 \text { months }\end{array}$} & Once & \multicolumn{2}{|c|}{19} \\
\hline & 2-3 times & \multicolumn{2}{|c|}{192} \\
\hline & 4-6 times & \multicolumn{2}{|c|}{307} \\
\hline & 7 or more times & \multicolumn{2}{|c|}{343} \\
\hline
\end{tabular}

patients' preferences for quality improvements to their care [14,15]. Improved car parking and up-to-date information were the most highly endorsed areas in need of improvement $[14,15]$. While these studies provide an indication as to what areas of improvement patients perceive as needed, additional information is still required if health service improvements that reflect patient perceptions and wishes are to be made. For instance, one of these previous studies focused on the perceptions of chronic care patients, receiving care from three hospital departments in New South Wales, Australia, including oncology, neurology and cardiology. While this study included the perceptions of cancer patients, the specific initiatives perceived by cancer patients as needing improvement were 
Table 3: Top 10 most endorsed general health service improvement items $(\mathrm{N}=860)^{*}$.

\begin{tabular}{|l|c|c|}
\hline Item & N & \% (95\% CI) \\
\hline Improved car parking & 481 & $56 \%(23,89)$ \\
\hline Provide up-to-date information on your treatment or condition progress & 159 & $19 \%(12,25)$ \\
\hline Provide access to good hospital catering & 145 & $17 \%(12,22)$ \\
\hline Help to maintain daily activities and healthy lifestyles & 129 & $15 \%(9.8,20)$ \\
\hline Provide information on possible financial assistance & 127 & $15 \%(13,17)$ \\
\hline Reduce the time spent waiting for your appointment & 124 & $14 \%(3.3,26)$ \\
\hline Provide information or help with physical symptoms or side effects & 118 & $14 \%(11,17)$ \\
\hline Provide information you can access at home about your condition and treatment & 118 & $14 \%(10,17)$ \\
\hline Support and information for family and friends & 114 & $13 \%(10,17)$ \\
\hline Provide information on how to handle a medical emergency & 92 & $11 \%(8.4,13)$ \\
\hline
\end{tabular}

*Cell totals may not equal total sample size due to missing values.

not explored [15]. The second study explored cancer patients' perceptions specifically, however, this study included only a subsample of patients participating in a larger study, and only focused on the association between the initiatives selected by patients and their quality of life [14]. Larger studies that include a diverse range of cancer patients from a range of treatment centres are needed. Such studies should explore both the broad and specific changes patients would like made to their care, as well as those characteristics associated with such changes. Understanding, the characteristics associated with the most frequently endorsed changes will help identify what future support and health service changes are most wanted by cancer patients. Obtaining such information will help to inform what quality improvements should be made to improve the delivery of patient-centred care provided to cancer patients.

\section{Aims}

To determine, among a sample of Australian cancer patients receiving chemotherapy at outpatient oncology clinics:

1. The most frequently endorsed general health service improvements selected by patients;

2. For the three most endorsed general health service improvements, the proportion of participants endorsing specific health service changes; and

3. The patient sociodemographic, disease and treatment characteristics associated with the most frequently endorsed general health service improvements by patients.

\section{METHODS}

\section{Design}

This paper reports data collected as part of a stepped wedge cluster randomised controlled trial that aimed to improve the delivery of patient-centred care to cancer patients receiving chemotherapy (ACTRN12614000702617). It also extends previous analyses presented from a sub-sample of patients taking part in the baseline component of this study [14]. As the intervention was not successfully implemented in any of the sites, assessing the effectiveness of the intervention was not possible. Consequently, this paper focuses on presenting an in-depth exploration of the quality improvements identified by a large sample of cancer patients, receiving treatment from a number of cancer treatment centres.

\section{Setting and Participant Eligibility}

Six outpatient oncology treatment units located in New South Wales, Australia, participated. Individuals were eligible if they: (i) were aged 18 years or older; (ii) were receiving chemotherapy for any cancer diagnosis; (iii) had attended the treatment unit on at least one previous occasion and therefore were considered able to reflect on aspects of the treatment centre care where they desired change; (iv) were able to complete an English-language survey either independently or with assistance; and (v) could provide informed consent.

\section{Recruitment}

Trained research volunteers approached patients in the waiting room or treatment area of the oncology unit and invited participation in the research. Potential participants were provided with awritten information statement and assessed for eligibility. Those who were eligible were invited to commence a survey on a tablet computer. Research volunteers recorded information regarding the gender and age of non-consenting participants to allow for determination of consent bias.

\section{Measurement}

Participants completed a survey on a tablet computer. Survey items were presented using the online survey system $\mathrm{QuON}$ [16]. The QuON system is a dynamic online survey platform which allows the use of dynamic branching to ensure participants only received relevant questions. Participants self-reported the following: (i) Socio-demographic information: gender, age, highest level of education, marital status, Aboriginal or Torres Strait Islander status, possession of a concession card, private health insurance status, and weekly family income; (ii) Disease andtreatment information:site of primary cancer; purpose of treatment; type of treatments received; number of visits to the out-patient clinic in the previous 3 months; (iii) Consumer Preferences Survey (CPS): The CPS is a web-based survey that assesses patients views as to which areas of their care could be improved. Patients are presented with 25 items that represent general areas of health care that are organised into four categories: (1) changes to appointment scheduling; (2) changes when arriving at an appointment, (3) changes during a clinical appointment, and (4) changes to assist with managing at home. For most of the 25-items patients are asked to indicate which areas they believe could be improved [14]. For those general health 
service improvements that patients select, they are then prompted to indicate what specific changes could be implemented to improve their care. The number of specific changes presented for patients to select varied from 3-11 depending on the general health service improvement selected. Patients could select as many specific health care changes as they wanted.

\section{Data analysis}

As the intervention was not successfully delivered as planned, data were analysed as an observational study. The top ten most frequently endorsed general health service improvements were calculated and reported. For the top three items, the frequency of patients selecting the specific initiatives suggested to improve these top three areas are also reported. For both of these outcomes, the frequency, percentage and $95 \%$ confidence intervals (CIs) are reported for each item. The delete-1 cluster jack-knife variance estimation method was used in the calculation of the $95 \%$ CIs to adjust for the clustered nature of the data and the variable cluster sizes. Logistic regression analyses were conducted for the most frequently endorsed general health service improvement item, to identify sociodemographic, disease and treatment characteristics associated with patients identifying this item as an area in need of change. The characteristics assessed in the model were hypothesised to impact on patient's perceptions of their care and included: age, sex, marital status, education status, private health insurance coverage, cancer type and number of visits to the clinic in the last three months. To control for any possible effect the intervention may have had on the study outcome, an intervention received variable was included in the regression model. For this variable, participants who completed a survey before the intervention begun at their hospital was coded as not have received the intervention, while patients who completed a survey after the intervention was attempted at their hospital were coded as receiving the intervention. The delete-1 cluster jack-knife variance estimation method was used to account for clustering by hospital site and for the variable cluster sizes. List wise deletion was used to remove observations with missing data from the model so that only complete cases were analysed. Characteristics identified at a p-value $<0.05$ on the Wald statistic were considered statistically significant. The logistic regression model was assessed for potential outliers and violations in the assumption of multicollinearity.

\section{Ethics Approval}

Ethics approval was provided by the Hunter New England Human Research Ethics Committee (13/08/21/4.07) and the University of Newcastle Human Research Ethics Committee (H-20120099). Appropriate governance approvals were obtained from all participating treatment centres. All participants provided informed consent for participation.

\section{RESULTS}

\section{Sample}

Of 1272 patients approached, 922 eligible patients agreed to participate ( $72 \%$ consent rate). A total of 879 patients initiated the CPS survey. Table 1 describes the sociodemographic characteristics and Table 2 details the disease and treatment characteristics of all eligible participants. Most (81.1\%) participants were aged between 50 and 69 years at the time of the study, were female $(55.4 \%)$, in a partnered relationship (65.3\%), and did not have private health insurance (60.9). The most common cancer type was blood (24\%) followed by breast (22\%). The most common cancer treatment received was chemotherapy $(93.7 \%)$.

Column totals may not add to total sample size due to missing values. Percentages may not add to 100 due to missing values.

\section{Top ten most frequently endorsed general health service improvements}

Out of the 25 general health service improvement items listed in the CPS, participants selected a median of two items for improvement (range 0 to 19). A total of 171 (20\%) patients indicated that they did not believe any of the CPS areas of care required improvement at their outpatient clinic, while 175 (20\%) indicated that five or more items required improvement. The top 10 most frequently endorsed general health service improvement items are provided in Table 3. The most frequently endorsed item was improved car parking (56\%). However, there was variation between hospitals with regards to the percentage of patients who selected this item as an area in need of improvement (reflected by the wide confidence intervals). Specifically, over $50 \%$ of patients from sites 2 (75\%), 4 (54\%), 5 $(68 \%)$ and $6(79 \%)$ selected this item as an area for improvement. Whereas, only $37 \%$ and $6.6 \%$ of patients selected this item from sites 1 and 3, respectively. The second most frequently reported quality improvement item was up-to-date information on the patient's treatment or condition progress (19\%), followed by having access to good hospital catering (17\%).

\section{Proportion of participants endorsing specific health service changes}

For each general health service improvement item that was endorsed, participants were asked to select from a list, which specific quality improvement initiatives they believe could help to improve that domain. Table 4 presents the percentage and frequency of patients who selected each of the specific initiatives related to the top three most frequently endorsed general health service improvement items for parking, information and catering.

Of the 481 patients who selected car parking as an area in need of improvement, 472 (98\%) selected at least one specific quality improvement initiatives for this domain. Reserved car parking for clinic patients was the most frequently selected initiative (63\%). Of the 159 patients who selected up-to-date information on their treatment or condition progress as an area for quality improvement, $135(85 \%)$ responded to the specific improvement initiatives listed for this domain. Knowing the status of their cancer (70\%) was the most frequently endorsed initiative. Of the 145 patients who endorsed access to good hospital catering as an area for quality improvement, 141 (97\%) answered the specific improvement initiatives listed for this area. Being able to order food from a cafe and have it delivered to the clinic if the patient is unable to leave was the most frequently selected initiative (62\%).

\section{Characteristics associated with the most frequently endorsed general health service improvement}

A total of 850 (98\%) observations were included in the multivariable logistic regression. Table 5 lists the sociodemographic, disease and treatment characteristics associated with the top general health service improvements selected by patients. Age was the only characteristic found to be significantly associated with patient's selecting 'improved car parking' as an area that could be improved. Compared to those aged 70 years and over, patients aged 18-49 
Table 4: Frequency and percentage of patients selecting the specific initiatives for improved car parking, information and catering.

\begin{tabular}{|c|c|c|}
\hline Issue & $\mathbf{n}$ & $\%(95 \% \mathrm{CI})$ \\
\hline \multicolumn{3}{|l|}{ Parking } \\
\hline Reserve spaces for clinic patients only & 297 & $63 \%(56,69)$ \\
\hline Reserve parking spaces close to the clinic & 185 & $39 \%(29,50)$ \\
\hline Provide affordable options for parking & 99 & $21 \%(12,30)$ \\
\hline Provide more disabled only parking spaces & 85 & $18 \%(7.6,28)$ \\
\hline Provide patient drop-off zones or short stay parking for caregivers & 78 & $17 \%(5.9,27)$ \\
\hline Provide easy to use parking machines & 24 & $5.1 \%(1.8,8.4)$ \\
\hline \multicolumn{3}{|l|}{ Information } \\
\hline Ensure you know the status of your condition & 95 & $70 \%(60,81)$ \\
\hline Ensure you are aware of the next steps in your treatment & 61 & $45 \%(34,57)$ \\
\hline Ensure you receive test results as soon as possible & 50 & $37 \%(26,48)$ \\
\hline Notify you before your appointment if your treatment has been changed by your doctor & 28 & $21 \%(8.0,33)$ \\
\hline \multicolumn{3}{|l|}{ Catering } \\
\hline The clinic is able to order from a cafe and items are delivered for those patients unable to leave & 87 & $62 \%(56,67)$ \\
\hline Ensure enough variety is provided for meals offered & 77 & $55 \%(48,62)$ \\
\hline Have hot and cold food options available in the hospital & 66 & $47 \%(30,63)$ \\
\hline Have biscuits and beverages available within the clinic & 26 & $18 \%(8.1,29)$ \\
\hline Have gluten free or vegetarian options available in the hospital & 17 & $12 \%(2.5,22)$ \\
\hline Provide a map and operating hours of cafes in the hospital & 16 & $11 \%(3.1,20)$ \\
\hline
\end{tabular}

Table 5: Characteristics associated with the most frequently endorsed general health service improvement item.

\begin{tabular}{|c|c|c|c|c|c|c|c|c|c|}
\hline Characteristic & $\begin{array}{l}\text { Characteristic } \\
\text { level }\end{array}$ & $\begin{array}{l}\text { Unadjusted } \\
\text { OR }\end{array}$ & $\begin{array}{l}\text { Unadjusted } \\
\text { lower } 95 \% \mathrm{CI}\end{array}$ & $\begin{array}{c}\text { Unadjusted } \\
\text { upper } 95 \% \mathrm{CI}\end{array}$ & $\begin{array}{l}\text { Unadjusted } \\
\text { p-value }\end{array}$ & Adjusted OR & $\begin{array}{c}\text { Adjusted } \\
\text { lower } \\
95 \% \mathrm{CI}\end{array}$ & $\begin{array}{c}\text { Adjusted } \\
\text { upper } \\
95 \% \mathrm{CI}\end{array}$ & $\begin{array}{c}\text { Adjusted } \\
\text { p-value }\end{array}$ \\
\hline \multirow[t]{2}{*}{ Education level } & $\begin{array}{l}\text { Bachelor or } \\
\text { Postgraduate } \\
\text { degree }\end{array}$ & 0.88 & 0.48 & 1.61 & 0.27 & 0.80 & 0.36 & 1.76 & 0.26 \\
\hline & $\begin{array}{l}\text { Diploma or } \\
\text { trade certificate }\end{array}$ & 0.76 & 0.36 & 1.57 & & 0.71 & 0.37 & 1.38 & \\
\hline Marital status & $\begin{array}{l}\text { Married or living } \\
\text { with a partner }\end{array}$ & 1.20 & 0.89 & 1.62 & 0.18 & 1.21 & 0.89 & 1.64 & 0.17 \\
\hline \multirow[t]{2}{*}{ Treatment goal } & Don't know & 1.04 & 0.52 & 2.07 & 0.97 & 1.17 & 0.60 & 2.31 & 0.84 \\
\hline & Slow growth & 0.97 & 0.55 & 1.72 & & 1.03 & 0.64 & 1.65 & \\
\hline \multirow[t]{2}{*}{ Age } & 18 to $49 y r s$ & 1.59 & 1.25 & 2.03 & 0.01 & 1.61 & 1.36 & 1.92 & $<0.001$ \\
\hline & 50 to 69yrs & 1.47 & 0.98 & 2.19 & & 1.58 & 1.03 & 2.43 & \\
\hline \multirow[t]{3}{*}{ Cancer type } & Blood & 1.09 & 0.29 & 4.06 & 0.47 & 1.32 & 0.44 & 3.98 & 0.47 \\
\hline & Bowel & 0.96 & 0.45 & 2.06 & & 1.15 & 0.53 & 2.49 & \\
\hline & Other & 0.84 & 0.42 & 1.70 & & 1.02 & 0.48 & 2.16 & \\
\hline $\begin{array}{l}\text { Clinic visits in the } \\
\text { last } 3 \text { months }\end{array}$ & 6 or more & 1.06 & 0.73 & 1.55 & 0.69 & 1.13 & 0.75 & 1.70 & 0.47 \\
\hline Sex & Female & 1.33 & 0.64 & 2.76 & 0.37 & 1.38 & 0.73 & 2.60 & 0.25 \\
\hline $\begin{array}{l}\text { Private health } \\
\text { insurance }\end{array}$ & No & 1.05 & 0.63 & 1.76 & 0.81 & 1.02 & 0.50 & 2.08 & 0.94 \\
\hline
\end{tabular}

years and 50-69 years had significantly higher odds of reporting this item as in need of improve

\section{DISCUSSION}

This study examined the most frequently endorsed general health service improvements selected by a sample of Australian cancer patients receiving outpatient chemotherapy using a newly developed measure, the Consumer Preferences Survey. It also identified the patient sociodemographic, disease and treatment characteristics associated with the most frequently endorsed general health service improvements.

Overall, one-fifth of participants did not endorse any of the suggested general health service improvements. These findings suggest that only a fifth of participating patients did not perceive that any of the pre-specified changes would improve their care, and were thus potentially satisfied with the care they received. This is in contrast to existing research that has examined cancer patient satisfaction with their treatment experience and the care they receive, which show that patients generally report very high rates of 
satisfaction [17-19]. In particular, a survey of more than 300 cancer patients attending six outpatient clinics in NSW found that more than $90 \%$ of patients thought that hospital staff showed them and their family respect, made sure they received correct treatment, and spoke to them in a way they could understand [20]. Alternatively, this finding may reflect that the domains assessed by the CPS were not comprehensive, and may not have identified general areas of potential change desired by participants. However, given a fifth of participants identified five or more areas that required improvement, this is unlikely.

Changes to car parking were identified by participants as the most important general health service improvement requiring change, with $56 \%$ of patients across all six clinics selecting this domain. This aligns with previous international research that has identified car parking as an important barrier to access to cancer services in the UK [21-23]. It also aligns with national research among patients attending chronic disease outpatient clinics, where $60 \%$ of respondents selected improved car parking as a domain in need of improvement using the CPS [15]. Age was the only characteristic found to be significantly associated with patient's selecting car parking as an area that could be improved.

The availability of parking for clinic patients only that is in close proximity to the treatment centre was identified as the most important specific change that could be made to improve car parking. This finding highlights the utility of using this dynamic approach to surveying patients as it provides specific and actionable changes to health services. It is important to note however that car parking was not a pertinent issue for all treatment centres. For two sites, less than $50 \%$ of patients identified car parking as an area in need of improvement. For one of these sites, less than $10 \%$ endorsed car parking as an area of change. This highlights the difficulties in generalising patient's perspectives on quality improvements across sites and emphasises the importance of assessing patient perspectives at the clinic level, and tailoring care towards the needs of patients attending specific treatment centres that have unique characteristics.

Six out of the top 10 general health service improvement items related to participant's desire for additional information about their cancer and its treatment. This finding is consistent with the unmet needs literature among cancer patients, where information needs have consistently been identified as a key area of unmet need for many patients $[5,23]$. The specific types of information desired by participants were personal information specifically related to their care and treatment, including knowing the status of their condition, the next steps in treatment, and receiving test results as soon as possible. These findings suggest the need for better communication of clinical information from the treatment team to their patients.

\section{STUDY STRENGTHS AND LIMITATIONS}

Strength of the current study is that it provides detailed data from a large sample of cancer patients across New South Wales. However, as there were only a small number of treatment centres and all treatment centres were located in one state of Australia, the generalizability of the findings to broader Australia and other countries is limited.

\section{CONCLUSION}

Achieving high quality cancer care requires understanding of the views and experiences of patients about the quality of care they receive. Car parking and access to information were the two most frequently endorsed general health service changes desired by this sample of participants. Future studies should examine whether enacting changes as per patient feedback improves patient perceptions of quality of care, and patient outcomes.

\section{REFERENCES}

1. Committee on Quality of Health Care in America. Institute of Medicine. Crossing the Quality Chasm: A New Health System for the 21st Century. Washington, DC: National Academy Press, 2001.

2. Dong S BP, Costa DS. The influence of patient-entered communication during radiotherapy education sessions on post-consultation patient outcomes. Patient education and counselling 2014; 95: 305-312.

3. Kahn KL, Schneider EC, Malin JL. Patient entered experiences in breast cancer: predicting long-term adherence to tamoxifen use. Medical care 2007; 431-439.

4. Venetis MK, Robinson JD, Turkiewicz KL. An evidence base for patient-cantered cancer care: a meta-analysis of studies of observed communication between cancer specialists and their patients. Patient education and counselling 2009; 77: 379-383.

5. Mallinger JB, Griggs JJ, Shields CG. Patient-cantered care and breast cancer survivors' satisfaction with information. Patient education and counselling 2005; 57: 342-349.

6. Stewart M. Towards a global definition of patient centred care. BMJ. 2001; 322: 444-445.

7. Reeves R, Seccombe I. Do patient surveys work? The influence of a national survey programme on local quality-improvement initiatives. Qual Saf Health Care. 2008; 17: 437-441.

8. Davies E, Cleary PD. Hearing the patient's voice? Factors affecting the use of patient survey data in quality improvement. Qual Saf Health Care. 2005; 14: 428-432.

9. Hall AE, Bryant J, Sanson-Fisher RW, Consumer input into health care: Time for a new active and comprehensive model of consumer involvement. Health Expect 2018.

10. Fradgley EA, Paul CL, Bryant J. Consumer participation in quality improvements for chronic disease care Development and evaluation of an interactive patient-cantered survey to identify preferred service initiatives. J Med Internet Res. 2014; 16: 292.

11. Carey M, Lambert S, Smits R. The unfulfilled promise: a systematic review of interventions to reduce the unmet supportive care needs of cancer patients. Support Care Cancer. 2012; 20: 207-219.

12. Fradgley EA, Paul CL, Bryant J. Consumer Participation in Quality Improvements for Chronic Disease Care: Development and Evaluation of an Interactive Patient-Centred Survey to Identify Preferred Service Initiatives. J Med Internet Res. 2014; 16:292.

13. Fradgley EA, Bryant J, Paul C. Cross-Sectional Data That Explore the Relationship Between Outpatients' Quality of Life and Preferences for Quality Improvement in Oncology Settings. J Oncology Practice. 2016 $; 12$

14. Fradgley EA, Oaul CL, Bryant J. Getting right to the point: identifying Australian outpatients' priorities and preferences for patient-centred quality improvement in chronic disease care. Int J Quality Health Care. 2016; 28: 470.

15. Paul D, Wallis M, Henskens F. QuON: A Generic Platform for the Collation and Sharing of Web Survey Data. In: WEBIST 2013 - 9th International Conference on Web Information Systems and Technologies 2013; 111-116.

16. Lis CG, Rodeghier M, Grutsch JF. Distribution and determinants of 
patient satisfaction in oncology with a focus on health related quality of life. BMC Health Services Research. 2009; 9: 190.

17. Nguyen TVF, Anota A, Brédart A. A longitudinal analysis of patient satisfaction with care and quality of life in ambulatory oncology based on the OUT-PATSAT35 questionnaire. BMC Cancer. 2014; 14: 42.

18. Heerdegen ACS, Petersen GS, Jervelund SS. Determinants of patient satisfaction with cancer care delivered by the Danish healthcare system. Cancer. 2017; 123: 2918-2926.

19. Tzelepis F, Hanna JH, Paul CL. Quality of patient-centred care: Medical oncology patients' perceptions and characteristics associated with quality of care. Psycho-Oncology. 2017; 26: 1998-2001.
20. Cancer Council New South Wales. Cap Parking for Cancer Patients in New South Wales. Sydney, NSW: Cancer Council NSW 2012.

21. Fradgley EA, Paul CL, Bryant J. Getting right to the point: identifying Australian outpatients' priorities and preferences for patient-centred quality improvement in chronic disease care. Int J Quality Health Care. 2016; 28: 470-477.

22. Morrison V, Henderson B, Zinovieff F. Common, important, and unmet needs of cancer outpatients. European J Oncology Nursing. 2012; 16: 115-123. 